\title{
Research on Immersion Teaching Method Based on 5G +XR Technology and Reinforcement Learning Model
}

\author{
Xueqing Xie $\mathbb{B}$ \\ Chongqing Industry Polytechnic College, Chongqing 401120, China \\ Correspondence should be addressed to Xueqing Xie; xiexq@cqipc.edu.cn
}

Received 14 December 2021; Revised 4 January 2022; Accepted 13 January 2022; Published 14 February 2022

Academic Editor: Qiangyi Li

Copyright (c) 2022 Xueqing Xie. This is an open access article distributed under the Creative Commons Attribution License, which permits unrestricted use, distribution, and reproduction in any medium, provided the original work is properly cited.

\begin{abstract}
The traditional teaching mode is difficult to meet the needs of modern teaching development because of its single teaching method and insufficient utilization of resources. With the in-depth application of $5 \mathrm{G}$ and XR technology in the field of education, the teaching mode based on $5 \mathrm{G}+\mathrm{XR}$ has become a research hotspot of educational informatization. Therefore, this paper proposed an immersive teaching method based on $5 \mathrm{G}+\mathrm{XR}$ technology and reinforcement learning model. By analyzing the characteristics and advantages of $5 \mathrm{G}$ technology in the field of teaching, this paper expounded that $5 \mathrm{G}$ technology not only had an important impact on the reform of modern teaching mode, but also can promote the development of immersive teaching. In addition, based on the analysis of XR teaching theory and its significance, an immersive XR teaching design method based on reinforcement learning model was proposed, and the working principle of immersive XR teaching system and the architecture method of teaching space were given. Finally, the construction scheme of immersive teaching scene based on 5G $+\mathrm{XR}$ and the design idea of immersive XR teaching method were put forward. The experiment showed that the immersive XR teaching method proposed in this paper was better than the traditional teaching mode, whether it was the students' learning effect of knowledge or their participation and experience in learning, which also verified that the method proposed in this paper had certain feasibility and superiority. The immersion teaching method based on $5 \mathrm{G}+\mathrm{XR}$ proposed in this paper can provide a reference for the reform and development of modern education and teaching mode.
\end{abstract}

\section{Introduction}

In recent years, new technologies such as $5 \mathrm{G}$ technology, virtual reality, artificial intelligence, and cloud computing have been widely used in the field of education and teaching and the construction of smart campus. Since the application of virtual reality technology in the field of education, the application and development of various forms of extended reality (XR) technology, including augmented reality (AR), virtual reality (VR), and mixed reality (MR), have been accelerated in the field of education [1]. In 1994, Burden and Philippe Coiffed proposed that virtual reality has the basic characteristics of imagination, interaction, and immersion $[2,3]$. The application of XR technology in the field of education has changed the traditional teaching methods to a great extent. It can not only provide learners with teaching scenes with real experience, but also solve the problems of teaching interaction and situational learning that are difficult to realize in traditional teaching through XR equipment. Therefore, it has broad development prospects in the field of teaching. With the support of $5 \mathrm{G}$ technology, the application of XR in the field of education will have a broader development space. 5G technology can provide the data transmission rate required in the field of education. By supporting the real-time audio and video transmission required by XR teaching, it can provide learners with immersive teaching experience and then provide support for students to deeply master the knowledge they have learned.

In recent years, with the rapid development of 5G technology, great changes have taken place in people's life, work, and study. 5G technology has the advantages of high transmission rate, low network delay, and low power consumption, which makes $5 \mathrm{G}$ technology better developed and applied in the field of education $[4,5] .5 \mathrm{G}$ technology not only overcomes the limitations of traditional technology to a great extent, but also can reconstruct the educational 
architecture and business, to promote the rapid development of education. Especially after the rapid development of $5 \mathrm{G}$ distributed network technology, the teaching mode based on XR technology has undergone fundamental changes. Users can experience large-scale $\mathrm{XR}$ education through lightweight XR terminals.

XR technology has promoted the rapid development of military, aviation, entertainment, and other fields to a certain extent. Moreover, with the organic integration of $5 \mathrm{G}+\mathrm{XR}$ technology, fundamental changes are taking place in the field of XR education. Immersive virtual reality can make learners feel immersive about virtual scenes. Virtual reality teaching scene makes learners feel that in the real classroom they can create a good learning environment for learners through remote services and share various teaching resources at the same time. Immersive virtual reality teaching platform provides teachers and students with a virtual space for interactive communication, which can not only improve teachers' teaching level, but also enhance learners' learning ability and level. However, how to organically combine the development of $5 \mathrm{G}$ technology with the needs of XR teaching is not only the key to solve the reform of modern education and teaching mode, but also a development direction of immersive teaching mode reform.

\section{Related Works}

In order to break the shackles of traditional teaching, the research on virtual reality technology and its application in teaching has attracted extensive attention of many scholars, among which the United States started earlier. Then, with the rapid development of computer software and hardware technology, especially graphic display technology, in order to meet the needs of national defense and aviation and aerospace applications " virtual reality technology has made great progress [6-8]. The interactive classroom provided by $5 \mathrm{G}$ technology can realize the all-round upgrading of the traditional teaching classroom. With the support of $5 \mathrm{G}$ technology, the network environment has no longer become the limiting factor of modern teaching. Connecting with teaching software and hardware equipment through $5 \mathrm{G}$ network, the information transmission and interaction between teachers and students and various intelligent devices will be more convenient. The development of $5 \mathrm{G}$ technology not only provides strong support for intelligent education to cultivate learners' creativity, but also expands its application scope through the integration with other related technologies.

Research shows that the combination of 5G technology with augmented reality (AR), virtual reality (VR), and mixed reality (MR) can make the teaching process more acceptable to learners. 5G technology can break the limitations of traditional teaching space, not only promoting interdisciplinary communication between teachers and students but also using virtual reality scenes to guide learners to strengthen learning and improve learners' learning ability. At the same time, 5G technology can fully and quickly transfer the existing teaching resources to learners and realize the interactive communication between teachers and learners through learners' various experiences. Comparison between traditional teaching and immersive virtual teaching is shown in Figure 1.

At present, 5G technology is mostly used in 5G industry private network construction, industrial Internet, and other fields, while the application research with $5 \mathrm{G}+\mathrm{XR}$ as the theme is still in its infancy, and most of them focus on theory and scheme design. With the support of $5 G+X R$ technology, learners can carry out real-time online learning through modern media such as wireless network and mobile device without the influence of traditional teaching mode and achieve certain learning goals without time and space constraints. Using the high-speed network performance, learners can learn live courses online or learn through smooth recording and broadcasting courses or downloading resources $[9,10]$. The wide use of $5 \mathrm{G}$ technology and Internet can facilitate learners to learn anytime, anywhere. At this time, teachers' teaching scenes are no longer restricted by the traditional classroom forms, but can abandon the traditional classroom teaching forms and choose teaching scenes that are conducive to learners to complete relevant teaching tasks. For example, the teaching method of live or video courses is adopted to teach, so that learners can experience better learning results. At the same time, through web-based teaching activities, teachers can not only interact with learners in real time, but also grasp the degree of learners' grasp of teaching content in time. This also further reflects the advanced nature of networked teaching mode.

Although 5G network system has been widely used in the field of teaching, and the teaching platform based on $5 \mathrm{G}$ can master learners' learning progress and learning effect in real time. However, with the continuous improvement of user needs, how to effectively combine accuracy and personalization in the teaching process has attracted extensive attention of relevant scholars, and it is also one of the hot issues that need to be deeply studied in the application of 5G technology in the field of education. 5G technology can be used to obtain massive data of learners. Through real-time analysis of big data, the processing results can be fed back to learners and teachers through relevant teaching platforms, to provide reference for truly reflecting learners' learning status and teachers' personalized training. $5 \mathrm{G}+\mathrm{XR}$ can promote personalized, real-time, and accurate teaching to a certain extent [11-13]. Using various conditions provided by 5G and VR technology, we can constantly transform the traditional teaching mode to the modern teaching mode. Through intelligent operation, we can not only improve the scientific level of teaching, but also promote the teaching process from traditional experience teaching to intelligent teaching.

\section{Teaching Method Reform Based on 5G + XR Technology}

3.1. Theoretical Basis of $5 G+X R$ Technology. Driven by the development of mobile communication technology, 5G technology has formed a system including a variety of communication network technologies. At present, 5G technology mainly involves 10 key technologies such as 


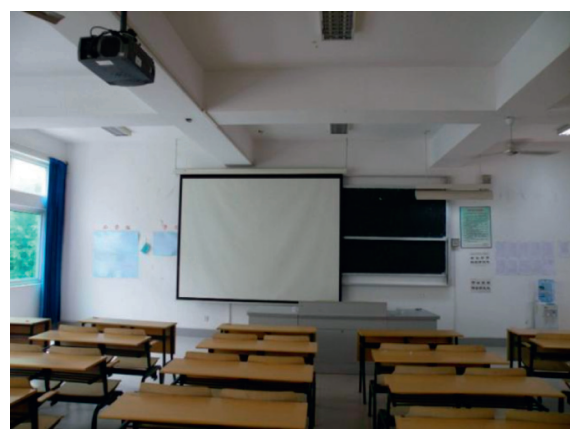

(a)

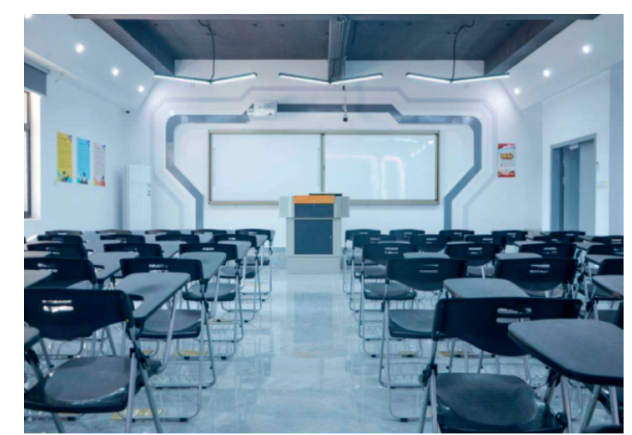

(b)

FiguRE 1: Comparison between traditional teaching and immersive virtual teaching. (a) Traditional teaching scene. (b) Immersive virtual teaching scene.

communication between people, machines and systems, information center network, mobile cloud computing, and context awareness technology. Compared with the 4G technology era such as cloud computing, Internet of things, artificial intelligence, and big data, 5G technology has the characteristics of intelligence, combination, humanization, and ubiquity. 5G technology can change the way of human information interaction to a great extent and promote the rapid development of all aspects. From the perspective of communication mode, $5 \mathrm{G}$ technology is conducive to the development of immersion communication. Immersive communication refers to the real-time communication of information through people and their related media, and the personalized and customized information release can be realized by using $5 \mathrm{G}$ technology.

The use of $5 \mathrm{G}$ technology has the advantages of being free from the influence of time and space when realizing information dissemination. The introduction of $5 \mathrm{G}$ technology in the process of teaching activities makes the resources required for teaching available everywhere, and teachers and students can obtain the required educational resources everywhere, which promotes the reform of all aspects of the teaching model. Because $5 \mathrm{G}$ technology has the characteristics of high transmission rate, low data transmission delay, high data capacity, large number of access users, low energy consumption, and low cost, the adoption of $5 \mathrm{G}$ technology is very favorable for building a new basic education environment.

XR technology includes augmented reality, virtual reality, hybrid reality, and other related technologies and will become a new immersive technology with the deepening of these technologies' mainly uses computer technology and various virtual reality devices to form real and virtual scenes and can realize human-computer interaction. From the perspective of technology application, $\mathrm{XR}$ is a comprehensive technology integrating Internet, artificial intelligence, Internet of things, and hybrid reality. It can not only make users get a better experience, but also change the existing lifestyle and education modern technology not only has the application advantages of $\mathrm{AR}, \mathrm{VR}, \mathrm{MR}$, and other technologies, but also can realize all-round real scene perception and user interaction with the support of XR technology. In addition, XR can be applied to a broader industry by integrating with $5 \mathrm{G}$, Internet of things, and other technologies. 5G technology and XR technology are the basis of realizing the fourth industrial revolution. Through technology integration, it can have an important impact on modern teaching.

3.2. Educational Function of $5 G+X R$. In order to meet the needs of educational informatization, 5G + XR technology has been gradually applied to online and offline teaching and continues to promote the development of relevant infrastructure, education platform, data fusion, teaching business, and user objects. The introduction of 5G core technology into the field of education provides a technical basis for the realization of educational informatization. Through the wide application of 5G network in the field of education, the leap of educational informatization from mobile terminal to wireless terminal is realized [14, 15]. As $5 \mathrm{G}$ technology breaks through the previous problem of limited $4 G$ bandwidth, the application of $5 G+X R$ technology in the field of teaching can not only solve the problems of slow and delayed transmission of teaching information, but also turn efficient virtual reality experiments, 3D interactive processing, multimedia network integration courses, and Internet of things courses into reality, so as to promote the continuous transformation of traditional education to intelligence and experience.

After 5G and XR technology are widely used in the field of education, especially teachers and students are used to $5 \mathrm{G}$ in the process of teaching activities. The function of $5 \mathrm{G}+\mathrm{XR}$ technology can also be directly applied to classroom teaching. This can promote not only the organic combination of $5 \mathrm{G}+\mathrm{XR}$ technology with classroom teaching and practice, but also the development trend of effective integration of $5 \mathrm{G}+\mathrm{XR}$ technology and education. The premise of realizing educational informatization is to realize intelligent education first, and $5 \mathrm{G}+\mathrm{XR}$ technology provides an important information technology foundation for realizing modern intelligent education.

Whether using traditional teaching methods or modern teaching modes, teaching activities are an important business in the education industry, and classroom teaching is the main way to carry out education. The application of $5 \mathrm{G}+\mathrm{XR}$ 
technology can enrich the content and methods of classroom teaching. Through the organic integration of $5 \mathrm{G}+\mathrm{XR}$ technology and other related information technologies, classroom teaching forms and teaching contents can be improved to a great extent. At the same time, the application of $5 \mathrm{G}+\mathrm{XR}$ technology in the field of education also puts forward higher requirements for teachers' professional learning and organizational ability.

The application of $5 \mathrm{G}+\mathrm{XR}$ technology in the field of education will change the traditional classroom teaching process from teachers to students. The discussion activities in the classroom will be dominated by students, to replace the traditional teaching method dominated by teachers. The teaching content is no longer determined by the traditional teachers' lesson preparation, but dynamically adjusted according to the students' learning process. The development of $5 \mathrm{G}+\mathrm{XR}$ technology is conducive to improving the informatization and intelligence of education and teaching activities. With the combination of $5 \mathrm{G}+\mathrm{XR}$ technology and education, various advanced teaching methods, remote classroom interaction, virtual reality, and augmented reality are used to enrich campus activities and effectively integrate various resources. Various advanced intelligent devices can not only provide convenient hardware facilities for modern teaching, but also enable students to feel the learning experience brought by $5 \mathrm{G}+\mathrm{XR}$ technology from different ways. The interactive behavior between teachers and students in immersive teaching is shown in Figure 2.

\section{Cloud XR Immersion Teaching Method Based on Reinforcement Learning Model}

4.1. Cloud XR Education Theory. Cloud XR adopts cloud computing and streaming technology to transmit information from the cloud to each terminal in the form of video stream through XR application and XR glasses. Cloud XR makes full use of cloud computing technology and organically combines cloud computing and XR technology, which can realize XR application and display operations that are difficult for traditional XR products.

In the organizational structure of cloud XR, XR applications are concentrated in the cloud, where they are calculated and processed, and the running results of $\mathrm{XR}$ applications are obtained. Through the processing of relevant technologies, the cloud operation results can obtain the corresponding video stream, which is transmitted to each terminal through the network and output on the XR display device. Using XR display device, user information can be sent to the cloud to run relevant XR applications, to realize the interaction between user terminal and cloud applications. The organizational structure of cloud XR can transfer various cloud operations to the terminal through the cloud $\mathrm{XR}$ application and the video output and information collection of XR glasses. The organization structure diagram of $\mathrm{XR}$ cloud platform is shown in Figure 3.

As an important part of cloud XR teaching theory, cognitive theory takes learning as a main part of personal development process. Learners' psychology and physiology usually fluctuate periodically in the learning process. The

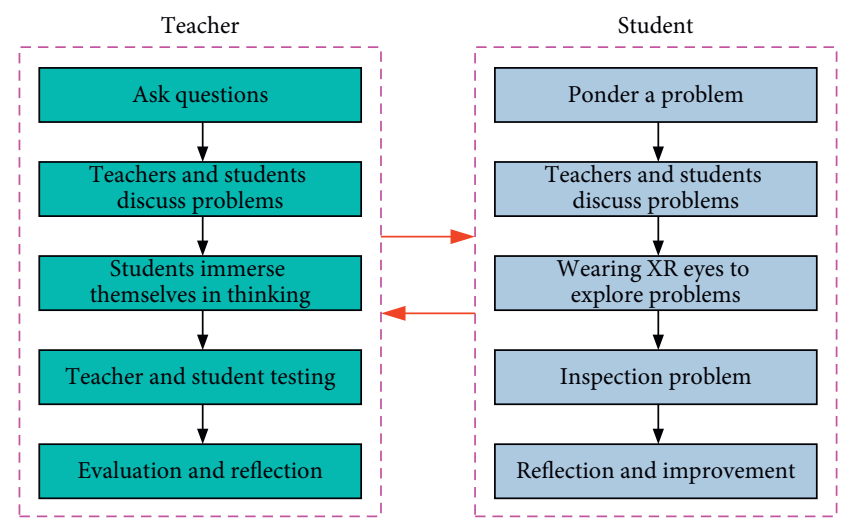

Figure 2: Interactive behavior between teachers and students in immersive teaching.

teaching theory corresponding to cognitive theory holds that people can continuously enrich learners' cognitive ability and improve learners' personal cognitive level through the continuous processing and improvement of self-cognitive process in the learning process. The interaction between learners and the external environment can continuously improve their cognitive level of things and their ability to adapt to the environment. Introducing XR technology into the field of education can bring a new modern teaching mode. This teaching model can start from the learners themselves, continuously improve the learners' knowledge structure and level, and let the learners continuously improve and develop in all aspects by strengthening the learners' personal experience and cognitive ability. As an important theoretical basis of cloud XR teaching model, constructivism usually requires that people's knowledge construction depends on their personal learning experience. Cloud XR teaching can help learners make use of rich teaching resources and advanced tools to improve learning efficiency and enable learners to strengthen their learning level through a process of cognition and understanding $[16,17]$. Constructivism theory holds that learners should not only deeply understand and remember the relevant theoretical knowledge, but also deeply understand the learned content in combination with specific problems, and then strengthen the training and application of the learned theoretical knowledge through personal learning experience. The learning process involves specific elements of situation, negotiation, and conversation, which is the learning environment provided by the cloud XR teaching model for learners.

Cloud XR teaching mode uses multimedia information technology to build a real teaching scene, so that learners can get better learning results in the real teaching scene. Cloud XR teaching method realizes the dialogue and negotiation between learners with the help of network media platform. It is a virtual teaching method that is not affected by time, space, and region. This cloud XR teaching method can use e-mail, virtual technology, or equipment to realize the negotiation and conversation problems that are difficult to solve in traditional teaching, and thus strengthen learners' understanding and mastery of all kinds of knowledge. Using 


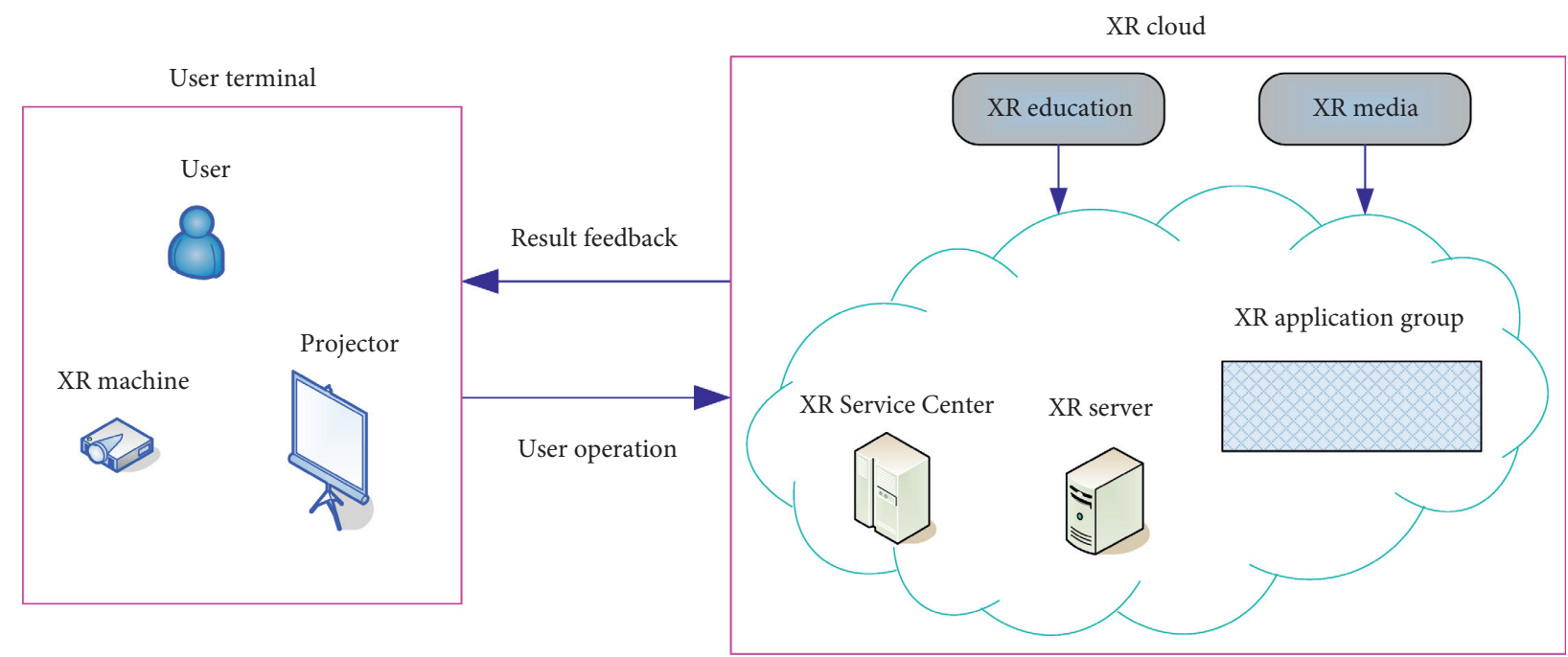

FIGURE 3: Organization structure diagram of XR cloud platform.

the cloud XR teaching mode can not only create a friendly and intuitive interactive learning environment for learners, but also stimulate learners to truly experience their interest in knowledge learning in the XR teaching scene environment by using a variety of senses.

4.2. Immersive $X R$ System. Using extended reality and its technical means can provide learners with an immersive learning experience environment, so that learners can truly feel the joy of learning in different teaching scenes. At present, XR technology mainly completes the construction of various realistic scenes through special devices such as helmets and displays. These XR devices can not only provide learners with closed real teaching scenes, but also create a virtual learning space with real experience. Learners can quickly enter a real virtual environment by using a variety of XR equipment such as sensors, data gloves, and control devices, so that they can devote themselves to learning and have a strong sense of immersion.

The XR system makes learners feel they are a member of the virtual reality scene through immersion and interacts with the virtual scene through XR helmets, data gloves, XR glasses, and other devices provided by the system $[11,12]$, so that learners' vision, hearing, and other senses can really focus on the virtual scene environment, to be separated from the real world. The composition of immersive virtual reality system is shown in Figure 4.

\subsection{XR Immersion Teaching Method Based on Reinforcement} Learning Model. Through immersive teaching mode, teachers, students, and resources can use XR scene to form interactive relationship. Virtual scene, role interaction, learner experience, and reflection are important parts of XR immersion teaching. Taking immersive teaching resources as the main object for learners to experience, according to the design requirements of $\mathrm{XR}$ teaching scene and the different needs of learners, an immersive XR teaching platform based on reinforcement learning model can be constructed [18]. As shown in Figure 5, as the main part of the immersive XR teaching platform, the middle part of the model includes virtual scene, role interaction, learners' experience, and reflection. The left side of the model is learners' learning behavior, and the right side of the model is the design behavior of XR teaching scene.

Extended reality scene can provide learners with a virtual learning space environment. It is an important place to integrate different learners' senses such as hearing, vision, and touch. Immersive XR teaching activities are completed in this virtual scene, so that learners can realize immersive learning experience for learners in the virtual scene through continuous real experience and mutual stimulation. In the composition of the model, the design task of XR scene is mainly completed by relevant developers. In the process of immersive learning, learners will acquire theoretical knowledge through the virtual teaching resources provided by the cloud XR platform.

As the main object of XR teaching activities, the interactive operation between teachers and learners is completed by the second layer of reinforcement learning model. It is not only the transition stage of different virtual learning spaces, but also an important stage for learners to carry out reinforcement learning. Immersive XR teaching usually adopts spatial interaction and selective interaction to realize role interaction. In this reinforcement learning model, the task of monitoring and managing learning behavior is mainly performed by the designer of virtual reality teaching management platform. Through the interactive behavior between learners and learning space, learners can fully feel the power brought by immersive VR teaching.

The third layer of reinforcement learning mode is used for learners' experience. It is an in-depth learning platform provided by XR teaching scene for learners. As a virtual scene learning platform, immersive XR teaching provides learners with immersive learning experience through the transformation of virtual space and the change of virtual scene. In this model, the designer of XR teaching scene mainly allows learners to participate in the whole process of 


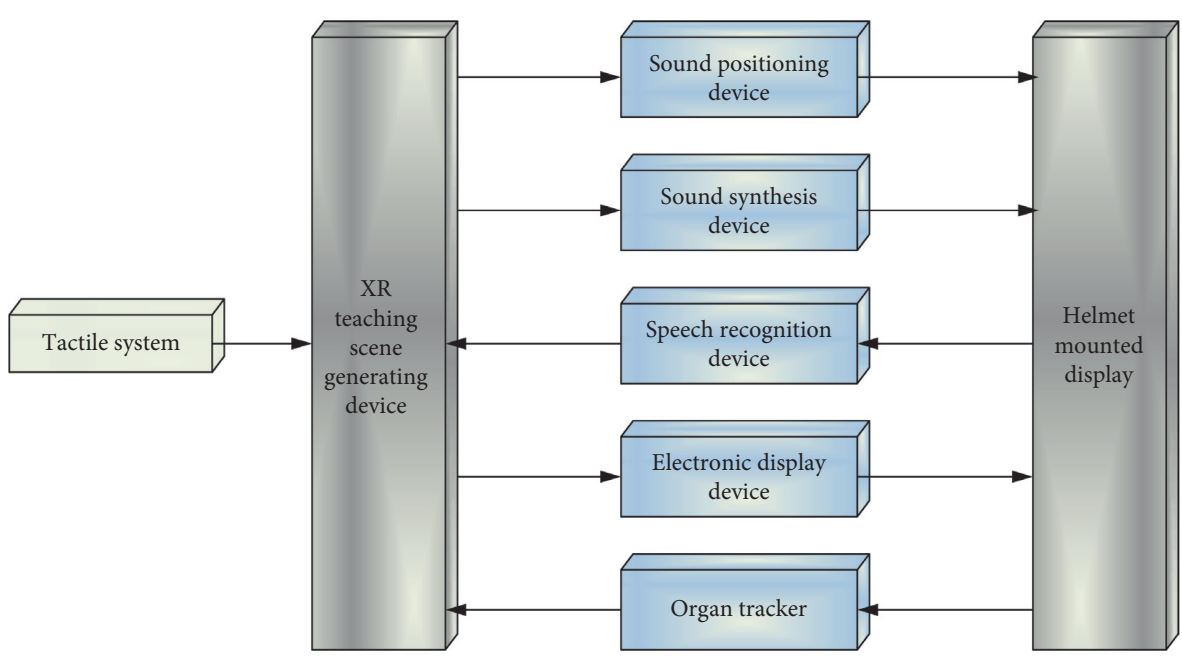

FIGURE 4: Schematic diagram of basic working process of immersive XR teaching system.

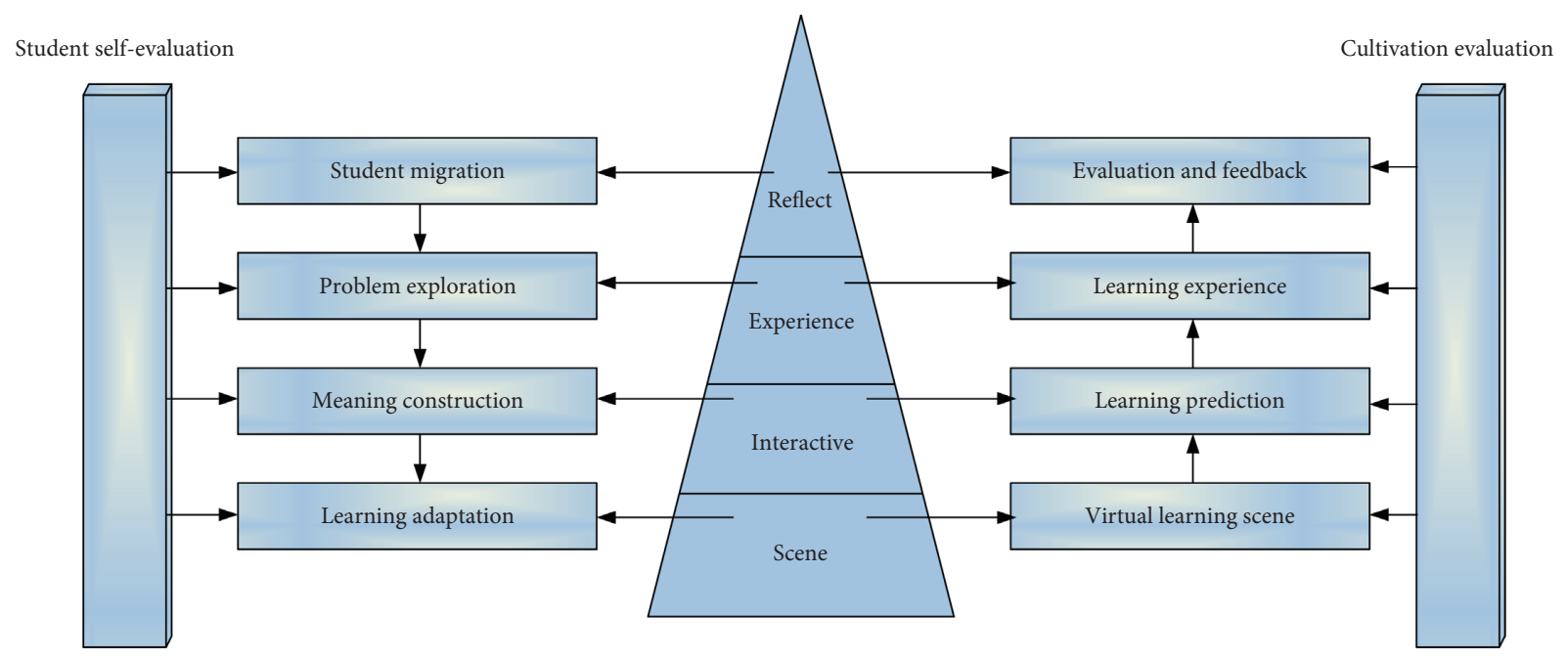

FIgURE 5: Construction of immersive XR teaching space.

teaching activities through learning experience design. Learner reflection is not only the top level of reinforcement learning mode, but also the main place for learners to conduct in-depth learning and real experience. As a virtual learning resource, immersive XR teaching designers should not only follow the basic rules of teaching resource development, but also reflect on the construction of virtual teaching resources. After the evaluation and feedback design of learners' learning effect, learners can reflect on their own virtual learning process.

\section{Immersive Teaching Design Based on 5G + XR Technology}

5.1. $5 G+X R$ Immersive Teaching Scene. Due to the rapid development of software and hardware technologies such as cloud computing, big data, and virtual reality facilities, the cost of hardware equipment required for $5 \mathrm{G}+\mathrm{XR}$ also decreases. The teaching mode with $5 \mathrm{G}+\mathrm{XR}$ as the main platform has laid a good foundation for the reform and development of the field of education. With the deep integration of 5G technology, XR technology, and education, the modern teaching mode will continue to develop in the direction of intelligence. $5 \mathrm{G}+\mathrm{XR}$ provides technical support for the construction of immersive virtual reality teaching scene. The virtual reality teaching scene based on $5 \mathrm{G}+\mathrm{XR}$ can stimulate learners' real experience in the classroom.

As shown in Figure 6(a), in the traditional teaching mode, due to the large number of classes and different student bases, it is usually difficult for teachers to carry out targeted teaching according to the individual differences of learners, which not only leads to poor teaching effect, but also may not stimulate students' understanding of the learned knowledge and learning enthusiasm. Using 5G + XR immersive virtual teaching method, the virtual teaching scene can provide learners with visual, vivid, and realistic teaching conditions, and learners can really experience learning with immersion from virtual teaching activities. Through this immersive virtual scene, learners are no longer limited to the traditional classroom teaching mode, but can complete various interesting teaching activities in different virtual scenes, as shown in Figure 6(b). 


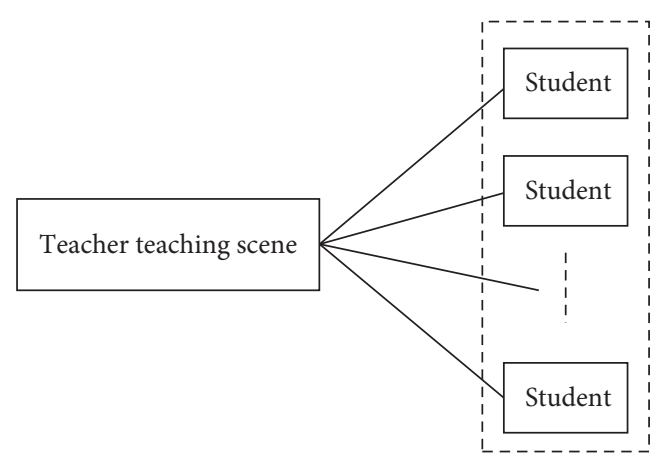

(a)

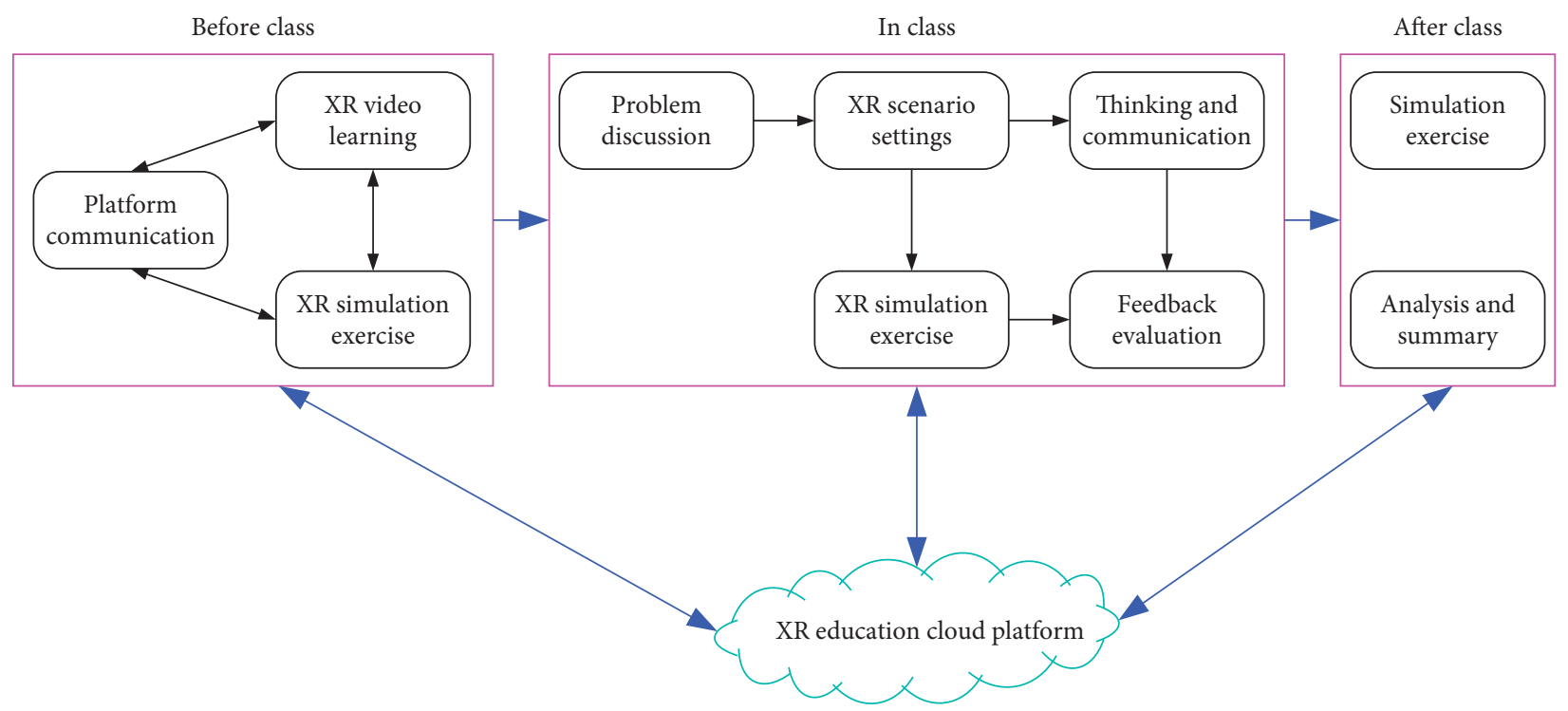

(b)

FIGURE 6: Construction of immersive XR teaching space. (a)Traditional teaching scene. (b)Immersive XR teaching scene.

Using this virtual teaching model can not only promote the transformation of learners from "learning knowledge" to "using knowledge" but also stimulate learners' initiative and enthusiasm through XR teaching scenes. Through immersive virtual teaching, it can not only cultivate learners' learning attitude, but also effectively improve learners' comprehensive ability. The construction of $5 \mathrm{G}+\mathrm{XR}$ cloud education platform can effectively expand the application scope of virtual teaching scenes and benefit more learners. Using $5 \mathrm{G}+\mathrm{XR}$ technology can provide learners with fast information service and support. Therefore, the virtual teaching scene based on $5 \mathrm{G}+\mathrm{XR}$ technology can provide learners with cloud services anytime and anywhere and obtain various virtual teaching resources from the learning cloud. Learners are no longer limited by traditional learning conditions. As shown in Figure 7, the virtual teaching platform based on $5 \mathrm{G}+\mathrm{XR}$ organically integrates XR with $5 \mathrm{G}$ cloud server. Using the big data storage and high-speed computing functions provided by $5 \mathrm{G}+\mathrm{XR}$ technology, the platform combines the network with super bandwidth and high-speed rate and virtual reality accessories. Learners usually use a XR terminal device to complete the learning tasks provided by the virtual teaching scene anytime and anywhere. Learners can not only truly feel the experience brought by immersive teaching, but also master more knowledge through various rich resources provided by cloud XR teaching platform.

5.2. Immersive Teaching Method Based on $5 G+X R$. Adopting the immersive virtual teaching mode will make the immersive virtual teaching content no longer limited by the classroom, laboratory, library, and other conditions required by traditional teaching. The virtual reality teaching scene based on $5 \mathrm{G}+\mathrm{XR}$ will make the teaching content no longer receive the space-time constraints of the real world and can realize the ubiquity and immediacy of the teaching content in the whole learning process of learners. At present, most of the teaching contents and teaching modes have widely adopted video teaching, online teaching, and other methods to provide learners with immersive learning conditions. Due to the previous $4 \mathrm{G}$ technology, the network is difficult to meet the conditions with high requirements for teaching contents. Therefore, with the application of 5G technology in the field of immersive teaching, some teaching contents can be obtained by learners anytime and anywhere through the virtual reality teaching platform and can use the favorable conditions provided by $5 \mathrm{G}+\mathrm{XR}$ for immersive learning and experience. 


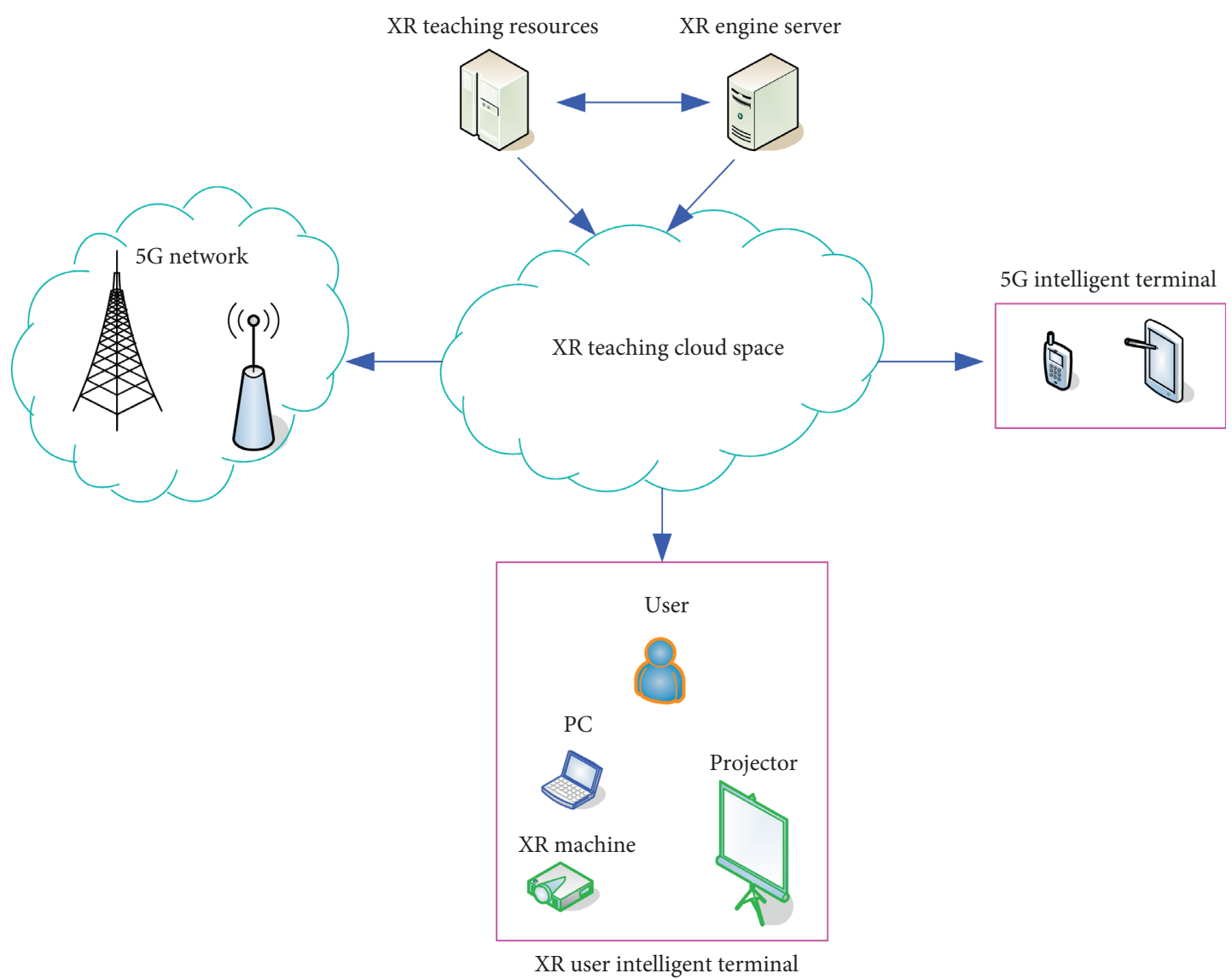

FIgURE 7: Construction diagram of $5 \mathrm{G}+\mathrm{XR}$ education cloud platform.

The teaching method of teaching students according to their aptitude has always attracted much attention in teaching. Due to the large individual differences of learners, using the previous online learning method not only makes it difficult for teachers' education and teaching methods to be effectively implemented according to the individual differences of learners, but also is not conducive to giving full play to learners' strengths [15]. New technologies such as big data, cloud computing, and artificial intelligence driven by $5 \mathrm{G}+\mathrm{XR}$ can better combine different learners' learning interests and ability to accept knowledge and adopt immersive XR teaching mode to design teaching methods and contents, to meet the learning needs of different learners.

Through $5 \mathrm{G}+\mathrm{XR}$ technology, teachers can obtain many learning process data about learners and timely grasp learners' learning dynamics and learning experience through data analysis of learning behavior. At the same time, teachers can use $5 \mathrm{G}+\mathrm{XR}$ technology to implement distance education and online education and provide learners with a suitable teaching and learning environment. Based on the immersive teaching platform of $5 G+X R$, teachers can analyze the online education dynamics in real time, and parents can master the children's learning dynamics in real time. Teachers can provide online guidance for learners and find the problems in the learning process in time by using the online teaching interaction function provided by the immersive virtual teaching platform. In addition, the immersive virtual teaching platform based on $5 \mathrm{G}+\mathrm{XR}$ technology can not only improve the teaching conditions, but also avoid the unfairness brought by traditional education and improve the distribution of educational resources.

The $5 \mathrm{G}+\mathrm{XR}$ teaching design scheme is shown in Figure 8. Firstly, one direct/video teaching classroom and $n$ receiving classrooms are constructed, and the real-time teaching scene of the virtual classroom is transmitted to the classroom where the learners are located through the $5 \mathrm{G}+\mathrm{XR}$ immersive virtual teaching terminal by using the characteristics of $5 \mathrm{G}+\mathrm{XR}$ technology, such as fast transmission rate, large amount of data storage, and realtime. Virtual reality technology is applied to students for all-round immersion teaching, so that students can understand teachers' virtual experiment operation and content explanation anytime and anywhere. In addition, teachers can use $5 \mathrm{G}+\mathrm{XR}$ virtual classroom terminal to master students' learning progress in real time and can interact with students in real time through the virtual teaching platform.

5.3. Challenges Faced by $5 G+X R$ Immersive Teaching. The application of $5 \mathrm{G}, \mathrm{XR}$, and other related technologies in the field of education needs to be gradually improved with the needs of education. At present, there are still some technical constraints in the application of $5 \mathrm{G}+\mathrm{XR}$ in the 


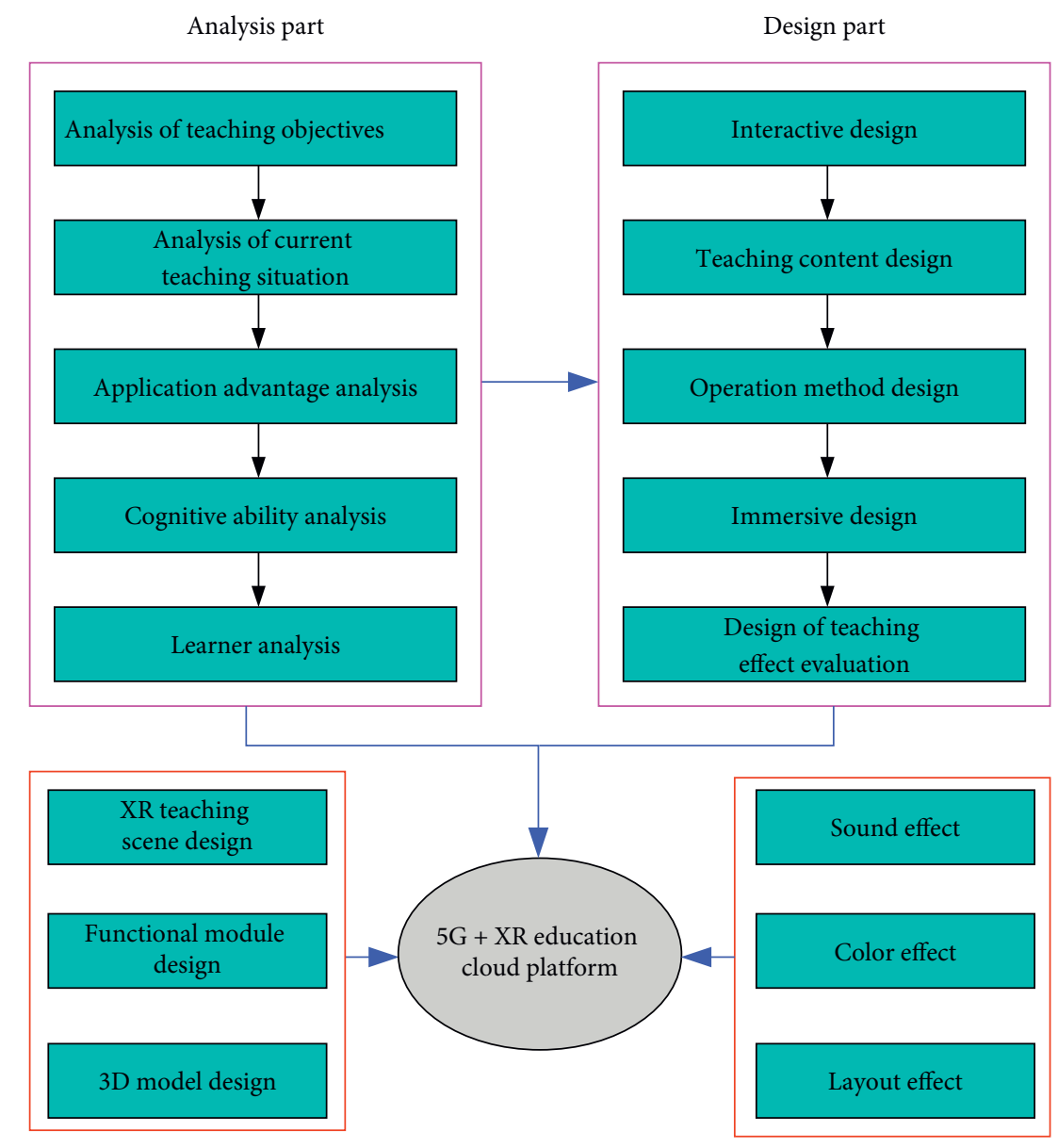

FIgURE 8: Schematic diagram of immersive virtual teaching method design.

field of education. For example, due to the high frequency and strong information transmission capacity, the wavelength is short and the coverage is small. Compared with $4 \mathrm{G}$ technology, the $5 \mathrm{G}$ network used for VR teaching requires a higher number of base stations, which also makes the current $5 \mathrm{G}$ network coverage difficult to meet the teaching needs. In addition, the key technical problems of VR also make it difficult to meet the rapid development of teaching and service requirements. $5 \mathrm{G}+\mathrm{XR}$ still has some technical bottlenecks that need to be broken through in the field of education.

$5 \mathrm{G}$ technology provides the foundation for XR teaching to a great extent, which not only solves the problem of time and space limitation of XR teaching, but also effectively reduces the cost of implementing $\mathrm{XR}$ teaching experience. Although the computing performance and network performance of big data are difficult to meet the needs of XR hardware, XR teaching content, and teaching system, with the strong support of $5 \mathrm{G}$ technology, the information interaction ability of XR has been greatly improved, and XR technology has been better applied to mobile terminals. With the decline in the cost of XR infrastructure, operators have used high-quality $5 \mathrm{G}$ network to provide special line network and $\mathrm{WiFi}$ infrastructure services for schools and relevant educational institutions in recent years [19]. $5 \mathrm{G}+\mathrm{XR}$ will be more and more widely used in the field of education. In addition, with the increasing coverage of $5 \mathrm{G}$ network and the continuous updating of XR equipment, the vertigo caused by XR virtual teaching can be gradually alleviated. Moreover, 5G network can realize some virtual teaching functions of XR through the cloud, which not only is conducive to learners to use XR terminals anytime and anywhere, but also greatly reduces the cost of traditional teaching.

\section{Teaching Application Cases and Analysis}

6.1. Experimental Objects and Materials. Choose 50 pupils in a school, aged between 10 and 12.40 people who did not understand the $\mathrm{XR}$ virtual teaching content were selected as the experimental objects and randomly divided into experimental group and control group. There was no significant difference in gender and age between the two groups.

The materials tested for the two groups of students are the same XR teaching content; that is, the knowledge and other contents learned by the two groups of students are the same. Therefore, the experimental independent variable can be set as the way of knowledge presentation.

In the experimental group, the tested experimental materials are XR course, which adopts the combination of $\mathrm{XR}$ teaching scene and intelligent interpretation. The devices used for learning are smart phones and XR glasses. The 
experimental materials of the control group were traditional video courses, which were presented by the combination of model display and knowledge explanation, and the learning equipment was a mobile phone.

6.2. Test means. Firstly, a knowledge pre-test questionnaire is designed to understand the learners' understanding of the learning content. The observation of students' positive emotion and negative emotion in the process of knowledge learning is mainly recorded by the self-designed positive emotion and negative emotion quantitative table. The score difference between students' positive emotions and negative emotions is regarded as students' emotional value. The test of students' learning effect is mainly to establish a questionnaire about the mastery of knowledge according to the teaching content and give corresponding scores according to the mastery of different knowledge. For the detection of students' learning load, the subjective evaluation method is mainly used, that is, to measure students' learning load from the difficulty of students' acceptance of the learned content and their own efforts.

6.3. Experimental Process and Data Analysis. The pre-test content of the experimental group mainly includes filling in the students' basic information, completing the knowledge pre-test questionnaire, and the positive emotion quantification form. At the same time, let students understand the methods of learning virtual courses. Students wear glasses and put mobile phones containing virtual courses into XR glasses so that students can learn XR courses. The formal test content of the experimental group is mainly the students' learning of XR course. The post-test content of the experimental group mainly includes helping students untie XR glasses and complete the questionnaire of cognitive load and the quantitative form of positive emotion.

The pre-test content of the control group mainly includes filling in the students' basic information and completing the knowledge pre-test questionnaire and emotion quantification form. At the same time, let students understand the method of learning virtual courses, that is, learn to watch mobile phone videos. The formal test content of the control group is mainly the students' learning of mobile video courses. The post-test content of the control group mainly includes the filling of the questionnaire of cognitive load and the questionnaire of emotion.

SPSS is used to detect the difference between the two groups of data.

\subsection{Experimental Results and Analysis}

6.4.1. According to the Test Results of Two Different Groups of Subjects, the Learning Style of the Course Determines the Influence of Students' Positive Emotions to a Great Extent. From the pretest results of the two groups of subjects, there is no significant difference in the positive emotions between the two groups, and the pretest results of the two groups have a great impact on the changes of positive emotions.
According to the posttest results of the two groups of subjects, the positive emotions of the subjects in the two groups were higher than those in the pretest results $(P<0.01)$, while the posttest results of the subjects in the experimental group showed that the positive emotions of the experimental group were significantly higher than those in the control group $(P<0.01)$. Comparison of emotion between the two groups before and after the test is shown in Table 1.

From the experimental observation results, compared with the traditional video teaching method, XR teaching method has a greater impact on students' positive emotions' teaching method which is conducive to students' better experience of the knowledge they have learned and also helps to stimulate students' learning enthusiasm.

From the questionnaire and test results of the subjects, it is found that, in the process of XR teaching, middle school students can pay high attention to the learning content through immersive experience and make full use of the learning environment. Some subjects believe that in the process of XR teaching they can effectively and quickly master the learned content by means of information communication such as three-dimensional sense and orientation sense. Therefore, when designing XR teaching, teachers should not only grasp the rational use of students' emotions, but also consider the different effects of visual and listening equipment provided by $5 \mathrm{G}+\mathrm{XR}$ technology, to design $\mathrm{XR}$ courses that are more conducive to students' emotional rendering.

6.4.2. From the Test Results of Two Groups of Different Objects, It Is Known That the Way of Displaying the Teaching Content Has a Great Negative Impact on Students' Cognition. According to the questionnaire survey results of the two groups of experimental subjects, there are great differences in cognitive load and psychological fluctuation between the experimental group and the control group $(P<0.01)$. Among them, the influence of students in the experimental group on cognitive load is significantly higher than that in the control group. As shown in Table 2.

It is not difficult to see from the experimental results that, for the same teaching content, different teaching methods will have a great impact on students. Among them, the cognitive load of the experimental group is significantly higher than that of the control group.

From the questionnaire survey and statistical results of the experimental subjects, it is found that some students in the experimental group feel dizzy due to wearing XR glasses during the experiment, which affects the effect of learning experience. The students in the experimental group have a curious psychology about using XR equipment, which affects the students' subjective perception. In addition, although the teaching contents of the two groups are the same, some students need to spend extra time to adapt to these new teaching methods because XR courses and teaching methods provide students with virtual teaching scenes and experience functions. 
TABLE 1: Comparison of emotion between the two groups before and after the test.

\begin{tabular}{|c|c|c|c|c|}
\hline Item & Experimental group & Control group & $t$ & $P$ \\
\hline Pretest mood & $1.58(0.762)$ & $1.63(0.915)$ & 0.13 & $>0.05$ \\
\hline Posttest mood & $3.8(0.637)$ & $2.6(0.728)$ & 2.7 & $<0.01$ \\
\hline $\mathrm{T}$ & 7.326 & 2.361 & 1 & 1 \\
\hline $\mathrm{P}$ & $<0.01$ & $<0.01$ & 1 & 1 \\
\hline
\end{tabular}

TABLE 2: Comparison of cognitive load between the two groups.

\begin{tabular}{|c|c|c|c|c|}
\hline Item & Experimental group & Control group & $t$ & $P$ \\
\hline Material perception difficulty & $4.62(0.852)$ & $3.58(0.753)$ & 3.261 & $<0.01$ \\
\hline Degree of effort & $4.84(0.726)$ & $3.26(0.618)$ & 3.157 & $<0.01$ \\
\hline
\end{tabular}

TABle 3: Comparison of learning effects between the two groups of students.

\begin{tabular}{lcccc}
\hline Item & Experimental group & Control group & $t$ & $P$ \\
\hline Learning acquisition ability & $45.168(5.364)$ & $38.326(6.328)$ & 3.528 & $0.01<P<0.05$ \\
Learning persistence & $37.247(3.637)$ & $26.158(3.169)$ & 2.482 & $<0.01$ \\
Ability in two weeks & $0.925(0.269)$ & $0.474(0.158)$ & 4.631 & $<0.01$ \\
\hline
\end{tabular}

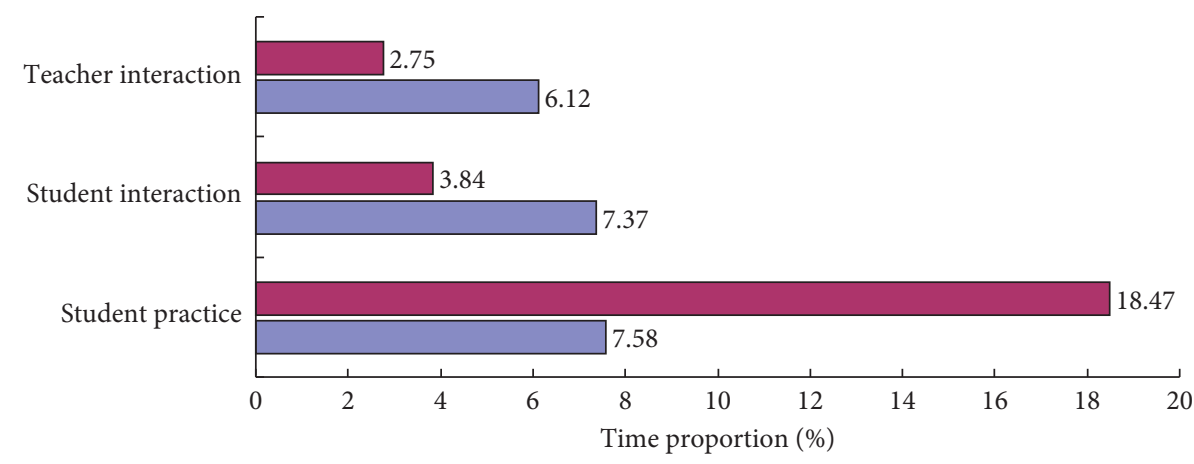

Experience group

Control group

FIgURE 9: Comparison results of actual operation and interaction time between the two groups.

6.4.3. From the Test Results of Two Groups of Different Objects, the Teaching Method of Teaching Content Has a Great Impact on Students' Test Scores. From the test results of the two groups of subjects, it is found that there are great differences in the scores of the two groups of students in the test of their learned knowledge $(P<0.05)$. Two weeks after the experiment, the two groups of students were tested. The results showed that the depth of knowledge cognition in the experimental group was significantly higher than that in the control group $(P<0.01)$, as shown in Table 3 .

From the comparison of the test results of the subjects' mastery of the learned knowledge, it is known that the XR immersion teaching method can make the students master the learned knowledge better, while the traditional teaching method makes it difficult for the students to achieve the ideal learning effect.

The knowledge acquired by students can be deeply rooted and not easy to be forgotten by using the immersive virtual teaching method, while the traditional teaching method allows students to only be taught the content they have learned. Therefore, these students are more likely to forget the knowledge they have learned over time.
6.4.4. From the Test Results of the Two Groups of Different Objects on the Interactive Time, Different Teaching Methods Have a Great Impact on the Interactive Operation Time of Students. From the comparison of the interaction between the two groups of subjects in the teaching process, we can know that the students in the experimental group spend more interaction time than the control group. In terms of interactive operation, the students in the experimental group have the most actual operation time. Among them, the interactive operation time of the students in the experimental group is $7.37 \%$, more than $6.12 \%$ of the teachers in the experimental group, while the interactive operation time of the students in the control group is $3.84 \%$, less than $2.75 \%$ of the teachers in the experimental group. From the comparison results of the two groups, the operation time of teachers in the control group is longer than that in the experimental group, and the interactive operation time of students in the experimental group is longer than that in the control group. The proportion of practical operation and interaction time of two groups of different objects is shown in Figure 9. 


\section{Conclusion}

In view of the shortcomings of traditional teaching facilities and means, this paper studied how to effectively integrate $5 \mathrm{G}+\mathrm{XR}$ technology and apply it to the field of education and teaching and put forward an immersive XR teaching method based on $5 \mathrm{G}+\mathrm{XR}$ and reinforcement learning model. Based on the analysis of $5 \mathrm{G}+\mathrm{XR}$ technology theory and its characteristics, this paper discusses the influence of $5 \mathrm{G}+\mathrm{XR}$ technology on the reform of modern teaching mode and the development of immersion teaching. Based on the analysis of the characteristics and significance of XR teaching, this paper expounds the design method of immersive XR teaching based on reinforcement learning model and the construction method of immersive XR teaching system and space. Finally, the construction scheme of immersive teaching scene based on $5 \mathrm{G}+\mathrm{XR}$ and the design idea of immersive $\mathrm{XR}$ teaching are given. The experiment shows that the immersive XR teaching method is superior to the traditional teaching mode in both students' learning effect of knowledge and students' participation and experience in learning. The immersion teaching method based on $5 \mathrm{G}+\mathrm{XR}$ technology proposed in this paper not only helps to adapt to the development of modern education and teaching mode reform, but also has certain reference and guiding significance for promoting the development of $5 \mathrm{G}$ and XR technology. With the continuous development of communication technology, computer level, and Internet application, how to effectively integrate $5 \mathrm{G}$ and XR technology to meet various teaching requirements in the future needs to be further explored.

\section{Data Availability}

The labeled dataset used to support the findings of this study is available from the author upon request.

\section{Conflicts of Interest}

The author declares no conflicts of interest.

\section{Acknowledgments}

This study was sponsored by Major Project of Higher Vocational Education and Teaching Reform in 2021: Innovation and Research of $5 \mathrm{G}+\mathrm{XR}$ Immersive Teaching Model (no. Z211011).

\section{References}

[1] K. Jan, P. Jeannette, and E. Theresa, "Explore augmented reality(AR), virtual reality (VR), and mixed reality (MR)for business," Business horisons, vol. 61, no. 2, pp. 3-5, 2018.

[2] P. Papathomas and K. Goldschmidt, "Utilizing virtual reality and immersion video technology as a focused learning tool for children with autism spectrum disorder," Journal of Pediatric Nursing, vol. 35, pp. 8-9, 2017.

[3] L. He and K. He, "Efficient memory-bounded optimal detection for GSM-MIMO systems," IEEE Transactions on Communications, vol. 99, pp. 1-15, 2022.
[4] N. Didehbani, T. Allen, M. Kandalaft, D. Krawczyk, and S. Chapman, "Virtual reality social cognition training for children with high functioning autism," Computers in Human Behavior, vol. 62, pp. 703-711, 2016.

[5] M. de Paiva Guimarães and B. B. Gnecco, "Teaching astronomy and celestial mechanics through virtual reality," Computer Applications in Engineering Education, vol. 17, no. 2, pp. 196-205, 2009.

[6] G. Lorenzo, A. Lledó, J. Pomares, and R. Roig, "Design and application of an immersive virtual reality system to enhance emotional skills for children with autism spectrum disorders," Computers \& Education, vol. 98, pp. 192-205, 2016.

[7] M. Bellani, L. Fornasari, L. Chittaro, and P. Brambilla, "Virtual reality in autism: state of the art," Epidemiology and Psychiatric Sciences, vol. 20, no. 3, pp. 235-238, 2011.

[8] M. R. Kandalaft, N. Didehbani, D. C. Krawczyk, T. T. Allen, and S. B. Chapman, "Virtual reality social cognition training for young adults with high-functioning autism," Journal of Autism and Developmental Disorders, vol. 43, no. 1, pp. 34-44, 2013.

[9] D. L. Williams, C. A. Mazefsky, J. D. Walker, N. J. Minshew, and G. Goldstein, "Associations between conceptual reasoning, problem solving, and adaptive ability in high-functioning autism," Journal of Autism and Developmental Disorders, vol. 44, no. 11, pp. 2908-2920, 2014.

[10] X. Lai and L. Fan, "Outdated access point selection for mobile edge computing with cochannel interference," IEEE Transactions on Vehicular Technology, vol. 99, pp. 1-10, 2022.

[11] Z. Merchant, E. T. Goetz, W. Keeney-Kennicutt, L. Cifuentes, O. Kwok, and T. J. Davis, "Exploring 3-D virtual reality technology for spatial ability and chemistry achievement," Journal of Computer Assisted Learning, vol. 29, no. 6, pp. 579-590, 2013.

[12] A. B. Gerth and J. Peppard, "The dynamics of CIO derailment: how CIOs come undone and how to avoid it," Business Horizons, vol. 59, no. 1, pp. 61-70, 2016.

[13] A. Mohammed, "Effectiveness of virtual reality game in foreign language vocabulary acquisition," Computers \& Education, vol. 153, Article ID 103893, 2020.

[14] F. Aïm, G. Lonjon, D. Hannouche, and R. Nizard, "Effectiveness of virtual reality training in orthopaedic surgery," Arthroscopy: The Journal of Arthroscopic \& Related Surgery, vol. 32, no. 1, pp. 224-232, 2016.

[15] E. Krokos, C. Plaisant, and A. Varshney, "Virtual memory palaces: immersion aids recall," Virtual Reality, vol. 23, no. 1, pp. 1-15, 2019.

[16] J. Radianti, T. A. Majchrzak, J. Fromm, and I. Wohlgenannt, "A systematic review of immersive virtual reality applications for higher education: design elements, lessons learned, and research agenda," Computers \& Education, vol. 147, Article ID 103778, 2019.

[17] C. A. Boulton, C. Kent, and H. T. P. Williams, "Virtual learning environment engagement and learning outcomes at a 'bricks-and-mortar' university," Computers \& Education, vol. 126, pp. 129-142, 2018.

[18] S. L. Farra, S. J. Smith, and D. L. Ulrich, "The student experience with varying immersion levels of virtual reality simulation," Nursing Education Perspectives, vol. 39, no. 2, pp. 99-101, 2018.

[19] J. Parong and R. E. Mayer, "Learning science in immersive virtual reality," Journal of Educational Psychology, vol. 110, no. 6, pp. 785-797, 2018. 